\title{
ESTUDO DOS MITOS E DA CONSTRUÇÃO NARRATIVA EM J. R. R. TOLKIEN
}

\author{
STUDY OF MYTHS AND THE CONSTRUCTION OF THE NARRATIVE IN J. R. R. \\ TOLKIEN
}

\author{
Emanuelle Garcia Gomes (UFU) ${ }^{1}$ \\ Fernanda Aquino Sylvestre (UFU) ${ }^{2}$
}

\begin{abstract}
Resumo
O presente artigo visa fazer um pequeno levantamento sobre as referências míticas na construção e corpo narrativo das obras fantásticas mais conhecidas do autor inglês J. R. R. Tolkien. $O$ Silmarillion contém contos que abordam fortemente a mitologia subcriada por ele, numa gama de referências de diversas sociedades e épicos de outrora. Conta com a gênese da Terra-Média e o estabelecimento dos povos que a constitui, passando assim a ser a história mítica de Arda. As menções deste livro se fazem presentes enquanto contos históricos passados de geração em geração nas demais narrativas do autor, como $O$ Hobbit e $O$ Senhor dos Anéis. Sob este aspecto mítico de suas narrativas, usamos como base, além de autores que estudam Tolkien, o mitólogo Joseph Campbell.
\end{abstract}

Palavras-chave: Mitos. Fantasia. Literatura.

\begin{abstract}
The present article aims to make a small survey on the mythical references in the construction and narrative body of the best known fantastic works of the English author J. R. R. Tolkien. The Silmarillion contains tales that strongly address the mythology sub-created by him, in a range of references from various societies and epics of yesteryear. It has the genesis of Middle-earth and the establishment of the peoples that constitute it, thus becoming the mythical history of Arda. The mentions of this book are present as historical tales passed down from generation to generation in the author's other narratives, such as The Hobbit and The Lord of the Rings. Under this mythical aspect of his narratives we use, as well as authors who study Tolkien, the mythologist Joseph Campbell.
\end{abstract}

Keywords: Miths. Fantasy. Literature.

O fato de o autor inglês J. R. R. Tolkien ser um filólogo contribuiu para a maestria de suas obras. O estudo da cultura, da geografia e principalmente da linguagem ajudou sobremaneira na criação de obras ambientadas no que o autor chamou de "Terra-Média", de

\footnotetext{
${ }^{1}$ Mestre em História pela Universidade Federal de Uberlândia.

${ }^{2}$ Professora do Instituto de Letras e Linguística da Universidade Federal de Uberlândia, onde atua na Graduação e no Programa de Pós-Graduação em Estudos Literários. Dentre outras publicações, coorganizou: A figuração da personagem na literatura europeia de língua italiana, francesa, alemã e italiana (2018); Literatura: digressão/transgressão (2016); Literaturas em diálogo: O Brasil e outras literaturas (2014).
} 
forma tão complexa, detalhada e artística que nos faz compreender o motivo de sua obra figurar como uma das mais significativas da literatura fantástica contemporânea.

O trabalho de um filólogo profissional é uma mistura engenhosa de história com estudos linguísticos. Ele procura compreender uma determinada língua não como uma estrutura estática, presa no tempo e no espaço, mas como um organismo vivo, que obedece a uma lógica interna de transformação, integrando mudanças de sentido, ao longo dos tempos, e mudanças formais das palavras (LOPES, 2002?). Dessa forma, o filólogo é, então, capaz de compreender, ao mesmo tempo, a história de uma língua, bem como a história do povo que a produziu.

Na universidade, Tolkien decidiu abandonar os estudos de letras clássicas para se dedicar, mais especificamente, à literatura e ao estudo do inglês antigo e médio. Um dos poemas anglo-saxões estudados por Tolkien - "Crist" - mostra-nos versos que chamam a atenção no que diz respeito ao estudo dos mitos:

Éalá Éarendel, engla beorhtast, / ofer middangeard monnum sended

("Salve, Éarendel, mais brilhante dos anjos / sobre a Terra - média enviado aos homens"). 'Terra - média' ou middangeard era um termo normal para designar o mundo em que vivemos, mas Éarendel era incompreensível, 'muito além do inglês arcaico', e excitou a imaginação de Tolkien (KYRMSE, 2003). ${ }^{3}$

O “Éarendel”, do poema anglo-saxão, tornou-se, mais tarde, o protótipo de "Eärendil”, o marinheiro e mensageiro da mitologia criada por Tolkien em $O$ senhor dos anéis. A história de Eärendil começa com seu nascimento na chamada Primeira Era e tem continuidade com o desejo do personagem pelo mar e por buscar as Terras Imortais, chamada Valinor, a fim de reencontrar seus pais e pedir aos Valar compadecimento com os elfos e os homens que sofriam nas guerras contra Morgoth. Eärendil é ajudado por Círdan, da Ilha de Balar, na construção de um barco, que permitiu ao personagem entrar em Valinor, vencer o exército do mal e lançar Melkor ao vácuo. Eärendil e sua esposa Elwing, após a vitória, seguem ao lado dos elfos e Eärendil viaja até hoje pelos céus, em Vingilot, onde sua estrela é sinal de esperança entre todos os elfos.

\footnotetext{
${ }^{3}$ Original: 'Éala, Éarendel, engla beorhtast, / ofer middangeard monnum sended, / And soðfæsta sunnan léoma, / Torht ofer tunglas - pu tída gehwane / of sylfum pé symle inlihtes (Éarendel. In: The Tolkien Wiki Community. Disponível em: http://www.thetolkienwiki.org/wiki.cgi?Mythology/\%C9arendel. Acesso em 8 de janeiro de 2018.)
} 
Há uma passagem importante na narrativa de Tolkien que mostra o começo dos tempos na Terra-Média e a importância de Eärendil :

\begin{abstract}
- E você, Portador do Anel - disse ela voltando-se para Frodo. - Dirijo-me a você por último, embora não seja o último em meus pensamentos. Para você, preparei isto. - Ergueu um pequeno frasco de cristal: brilhava quando ela o virava em sua mão, e raios de luz branca emanavam dele. - Este frasco - disse ela - contém a luz da estrela de Eärendil, engastada nas águas de minha fonte. Brilhará ainda mais quando a noite cair ao seu redor. Que essa luz ilumine os lugares escuros por onde passar, quando todas as outras luzes se apagarem. Lembre-se de Galadriel e de seu Espelho! (...) (TOLKIEN, 2001).
\end{abstract}

A estrela de Eärendil leva esperança a todos os povos da Terra-Média. Na mitologia de Tolkien, assim como em qualquer mitologia que tenhamos conhecimento, como a grega, a nórdica ou a hindu, por exemplo, a relevância de uma história, seja ela qual for, traz certo sentido à vida, ao espírito e à vivência em sociedade. Joseph Campbell, estudioso americano de mitologia e religião comparativa, traça uma definição de mito voltada não para a busca do sentido da vida, mas para a aquisição de experiência de vida. De acordo com o autor, ao entrarmos em contato com os mitos, somos capazes de captar a mensagem dos símbolos que são apresentados nas literaturas míticas. Campbell afirma, também, que o tema básico de toda mitologia é o de que existe um plano invisível sustentando o visível. Em outras palavras, o que sabemos é sustentado pelo que não sabemos. Essa ideia de "sustentação invisível”, relacionase com a sociedade (CAMPBELL \& MOYERS, 1990):

A sociedade aí estava, antes de você; continua aí, depois que você se vai, e você é um membro dela. Os mitos que o ligam ao seu grupo social, os mitos tribais, afirmam que você é um órgão de um organismo maior. E a sociedade, por sua vez, também é um órgão de um organismo ainda maior, que é a paisagem, o mundo no qual a tribo se move. O tema básico do ritual é a vinculação do indivíduo a uma estrutura morfológica maior do que a do seu próprio corpo físico (CAMPBELL \& MOYERS, 1990).

Tolkien talvez tenha conseguido transmitir este senso de experiência de vida a toda Arda, o universo, de forma coesa e significativa. Mostrando certa continuidade de memória, somos capazes de encontrar essa experiência não só nas histórias que envolvem Eärendil, como também em outra, por exemplo a história de Lúthien e Beren. Esta última tem tanta significância 
para os próprios personagens criados por Tolkien que, por ser uma narração mais antiga de antepassados daqueles que vivem a Guerra do Anel, tem ressonância na história de Aragorn e Arwen. Arwen, a elfa mais bela da Terceira Era, "reencarnação" de Lúthien, apaixona-se por um homem mortal, Aragorn, e renuncia sua imortalidade em nome do amor. O senso de experiência e memória estão presentes no decorrer da narrativa da trilogia de $O$ Senhor dos Anéis, colocando as sociedades da Terra-Média em contato com seu próprio passado, sua história e sua origem.

Tolkien sempre adorou sagas e conhecia muitos mitos, especialmente os de origem nórdica. Seu desejo de criar histórias semelhantes para a Inglaterra era latente. Embora não sejam entendidas normalmente como um documento histórico, como algumas obras conhecidas por essa razão, como a Ilíada e a Odisseia, todas as narrativas que têm a Terra-Média como palco refletem em escritos tais que ambientam um lugar e histórias de povos muito semelhantes aos contados nos tempos de antes ou de pouco depois de Cristo. Há escritos da gênese do mundo de Arda em $O$ Silmarillion, mostrando o começo dos tempos, em que "semi-deuses" conviviam com homens, elfos e anões, em batalhas e feitos. Encontramos aventuras como $O$ Hobbit e $O$ Senhor dos Anéis que apresentam vários personagens, com diferentes tipos de heróis, objetos mágicos, disputas mal versus bem, profecias, famílias, reis reivindicando tronos, sábios indicando conselhos aos seus seguidores, dragões, trolls, criaturas ferozes do submundo e batalhas.

O Silmarillion é, mais especificamente, a narrativa que contempla a origem da TerraMédia. Apesar de vários semi-deuses surgirem em uma forma humana para prezar e zelar pelas terras criadas, a partir da Canção dos Ainur, Tolkien cria um universo sob a égide de um só deus, Eru Ilúvatar. Esses semi-deuses, que fazem parte da canção de criação, são como uma espécie de anjos ou santos do catolicismo. Tolkien foi criado sob a doutrina católica e suas narrativas são muito influenciadas por ela.

Por meio da narrativa de $O$ Silmarillion conhecemos o começo de tudo, a criação do universo, o começo das vidas, o princípio do mal, as primeiras batalhas, as primeiras eras e as razões que deram fim a elas e início a outras.

Aproveitando pequenos mitos e lendas supostamente antigas, Tolkien escreveu o que seria o prelúdio das sagas $O$ Hobbit e $O$ Senhor dos Anéis. A sequência mais regular de leituras das obras de Tolkien seria $O$ Silmarillion, O Hobbit e, por fim, O Senhor dos Anéis, seguindo 
uma cronologia de eras, o começo, o meio e o fim de Arda. Após o lançamento e o sucesso de O Hobbit (lançado em setembro de 1937), Tolkien tentou vender a ideia de $O$ Silmarillion para sua editora, que a recusou, achando mais viável publicar "mais uma história de hobbits" (WHITE, 2002). Por apelo do editor, Tolkien começou a trabalhar nos ganchos que poderiam configurar a narrativa que compõe $O$ Senhor dos Anéis, mas nunca abandonou os escritos de $O$ Silmarillion, sempre relidos e revisados. A publicação acabou ocorrendo apenas após sua morte, numa edição organizada por seu filho.

O Hobbit, O Silmarillion e O Senhor dos Anéis contemplam uma tríade de começo, meio e fim, com poucas lacunas e muito semelhantes a lendas que foram escritas em tempos de narrativas orais. Apesar de díspares, é como se $O$ Silmarillion equivalesse às histórias do panteão grego em seu começo, com as primeiras batalhas de titãs e a convivência de deuses e homens e $O$ Hobbit equivalesse à Ilíada, enquanto $O$ Senhor dos Anéis corresponderia à Odisseia de Homero. Juntos, os três livros de Tolkien refletem a história de Arda, com todos os detalhes cabíveis construídos pela mente criativa do escritor.

Na introdução feita por Bill Moyers, no livro O Poder do Mito, em que ele estabelece uma conversa com o estudioso Joseph Campbell, Moyers ressalta a seguinte questão:

Matthew Arnold acreditava que a quintessência do espírito crítico consiste em "conhecer o melhor do que é conhecido e ensinado no mundo, e, por seu lado, tornar isso conhecido, criar uma corrente de idéias verdadeiras e estimulantes.' Assim fez Campbell (CAMPBELL \& MOYERS, 1990).

Pressupomos que assim também fez Tolkien, atingindo a meta que imaginava nas narrativas que criou. Tudo o que escreveu sobre a Terra-Média, muito provavelmente era deveras estimulante para ele.

Em Sobre Histórias de Fadas, Tolkien propõe discutir o que são essas histórias, a origem delas e para que servem. Para Tolkien, as que são consideradas de fadas, que se passam no "Belo Reino", revelam a relação dos homens com o espaço em que vivem e com seus habitantes. As histórias de fadas, nada mais seriam do que histórias de homens no Belo Reino e não sobre os seres encantados que lá habitam. Uma narrativa de aventuras com viajantes, não é histórias de fadas, uma vez que não se passa no Belo Reino e sim no nosso próprio mundo. A 
linguagem é o ponto fundamental no que se refere à origem dessas histórias, e o poder de criação se deve ao adjetivo, como Tolkien relata no trecho abaixo:

Mas ainda assim a Linguagem não pode ser descartada. A mente encarnada, a língua e o conto são contemporâneos em nosso mundo. A mente humana, dotada dos poderes de generalização e abstração, não vê apenas grama verde, discriminando-a de outras coisas (e contemplando-a como bela), mas vê que ela é verde além de ser grama. Mas quão poderosa, quão estimulante para a própria faculdade que a produziu, foi a invenção do adjetivo: nenhum feitiço ou mágica do Belo Reino é mais potente. E isso não é de surpreender: tais encantamentos de fato podem ser vistos apenas como uma outra visão dos adjetivos, uma parte do discurso numa gramática mítica. A mente imaginou leve, pesado, cinzento, amarelo, imóvel, veloz também concebeu a magia que tornaria as coisas pesadas leves e capazes de voar, transformaria o chumbo cinzento em ouro amarelo e a rocha imóvel em água veloz. Se era capaz de fazer uma coisa, podia fazer a outra, e inevitavelmente fez ambas. Quando podemos abstrair o verde da grama, o azul do céu e o vermelho do sangue, já temos o poder de um encantador em um determinado plano, e o desejo de manejar esse poder no mundo externo vem a nossa mente. Isso não significa que usaremos bem esse poder em qualquer plano. Podemos pôr um verde mortal no rosto de um homem e produzir horror, podemos fazer reduzir a rara e terrível lua azul, ou podemos fazer com que bosques rompam em folhas de prata e os carneiros tenham pelagem de ouro, e pôr o fogo quente no ventre do réptil frio. Mas numa 'fantasia', tal como a chamamos, surge uma nova forma: o Belo Reino vem à tona, o Homem se torna subcriador (TOLKIEN, 2010).

De acordo com Tolkien (2010) é, então, a partir da linguagem que o homem altera a paisagem ao seu redor, recria tudo aquilo como uma nova realidade, cria uma segunda realidade, um mundo secundário perfeitamente possível. Dessa forma, esta nova realidade não nega nem o afasta do real. Assim, podemos concluir que tudo que é logicamente possível pode ser representado por um mundo secundário.

Ler $O$ Senhor dos Anéis como mera alegoria da Segunda Guerra Mundial é um ato possível de interpretação, mas extremamente empobrecedor diante de um universo em que a imaginação poética envolve, numa teia coerente e complexa, uma multiplicidade de temas como o mítico, o literário e o histórico. 
A Teoria dos mundos possíveis, desenvolvida principalmente por Lubomir Dolezel, ${ }^{4}$ realiza uma aproximação semântica ao fato ficcional, isto é, aproxima através de seu significado e não de sua forma externa. Baseando-se em propostas apontados por autores como $\underline{L e i b n i z}^{5}$, a teoria dos mundos possíveis sustenta que toda ficção cria um mundo semanticamente diferente do mundo real, específico. Assim, uma obra de ficção pode alterar ou eliminar algumas das leis físicas imperantes no mundo real (como sucede na ficção científica e na novela fantástica), ou bem as conservar e construir um mundo próximo - se não idêntico - ao real (como sucede na novela realista). ${ }^{6}$

As histórias de Tolkien na Terra-Média situam-se no campo dos mundos possíveis heterocósmicos, pois um mundo heterocósmico é um mundo que não é uma versão do que é possível em relação ao nosso mundo, do ponto de vista histórico, lógico, físico, mas uma versão artística de elementos de outros mundos. O heterocósmico é inverossímil em nosso mundo, mas possível em si, ele possui uma configuração que não é válida no mundo dito real, mas que poderia ser válida em outro tipo de mundo. Do ponto de vista histórico, um mundo heterocósmico seria um mundo que tivesse uma sequência dos fatos que não fosse uma variação da história do mundo, mas que fosse uma história em si possível e que para existir teríamos que pressupor outro mundo. ${ }^{7}$

Esta aproximação semântica à ficção tem a vantagem de explicar, como é possível realizar julgamentos de verdade ou falsidade a respeito de afirmações ficcionais: seriam verdadeiros aqueles enunciados que cumprem com as regras próprias do mundo possível criado pela ficção (como, por exemplo, o poder que o anel exerce nos personagens em $O$ Senhor dos Anéis); seriam falsos aqueles que infringem as regras do mundo possível (como, por exemplo, afirmar que "os hobbits têm asas" em $\underline{O \text { Senhor dos Anéis })}$.

\footnotetext{
${ }^{4}$ Lubomir Dolazel é um teórico literário tcheco, um dos fundadores da teoria da ficção, autor de Heterocosmica, ficção e mundos possíveis.

${ }^{5}$ Gottfried Wilhelm Von Leibniz foi um filósofo, cientista, matemático e diplomata alemão que, assim como Isaac Newton, desenvolveu o cálculo moderno, em particular a Integral e Regra do Produto. É conhecido também em outros campos além da matemática e da física, como religião, política e filosofia. Neste último campo desenvolveu teorias sobre Mônada - esse termo para ele significa substância simples; e, assim como tal, faz parte dos compostos, sendo ela própria sem partes e portanto, indissolúvel e indestrutível.

${ }^{6}$ CARVALHO, Jairo D. Os usos estéticos do conceito de mundos possíveis de Leibniz. 2009. Além desse texto, foi usado leituras de resumos de aulas para o curso de Estética, na graduação de Filosofia na Universidade Federal de Uberlândia, ministradas pelo professor doutor Jairo Dias Carvalho.

${ }^{7}$ Idem.
} 
A fantasia heróica ou fantasia épica é um subgênero do gênero fantástico heterocósmico, presente principalmente na literatura, mas também vista nos cinemas e seus filmes de teor fantásticos.

Uma característica comum à grande parte das obras de fantasia épica contemporânea é que os protagonistas levam uma vida convencional até que, imprevisivelmente, uma anomalia muda suas vidas por completo. Assim como na literatura, muitos filmes também apresentam essa mesma característica. Personagens, que não têm uma rotina atribulada ou aventuresca deparam-se com uma herança que modifica toda sua vida, são escolhidos para cumprir uma missão, descobrem dons mágicos ou sobrenaturais. Esta característica costuma estar presente na fantasia em geral, em que os protagonistas são quase sempre precoces, como Frodo Baggins, em $O$ Senhor dos Anéis, que recebe o anel de seu tio e tutor, Bilbo, que, no passado, partiu com 13 anões e encontrou por acaso um gosto por aventuras e um ser chamado Gollum, com quem acabou disputando em um jogo de advinhas a posse do Anel do Poder, forjado por Sauron, muito tempo antes deles, no fim da Primeira Era. Notamos, então, que na literatura de fantasia épica contemporânea, criaturas ingênuas, crianças ou adolescentes, diferentes dos demais em algumas características impostas pela sociedade, deparam-se com possibilidades de provarem suas capacidades e empreenderem longas viagens em que encontram aventuras e desventuras.

Atualmente alguns autores falam de literatura fantástica para se referir à fantasia épica, mas esta denominação é errônea, já que existem obras, escritas e visuais, que embora fantásticas não podem ser consideradas épicas. Podemos citar como exemplo desse equívoco a série Harry Potter. A saga Harry Potter não deveria ser considerada épica, apesar de apresentar algumas nuances míticas. Ela é certamente uma fantasia, com a presença de um mundo paralelo, perfeitamente possível, com animais e seres fantásticos, como elfos, lobisomens, dragões, cachorros de 3 cabeças, além é claro, da presença da própria magia.

A literatura de fantasia épica cumpre a premissa de que tanto quem a escreve como quem a lê sabe que os acontecimentos narrados são ficção. Desse modo, ainda que encontremos literatura aparentemente deste tipo em obras como o poema de Gilgamesh $^{8}$ ou Odisseia de Homero, essas obras não são consideradas fantasias épicas, são obras apenas épicas, já que os

\footnotetext{
${ }^{8}$ A epopeia de Gilgamesh é um antigo poema épico da Mesopotâmia. Acredita-se que sua origem vem de lendas e poemas sumérios contando a história do deus e herói Gilgamesh. As histórias foram reunidas e compiladas no século VII a. C. Por Assurbanipal - o último grande rei dos Assírios.
} 
elementos mitológicos ou mágicos nelas presentes eram em suas respectivas épocas parte das crenças daquelas sociedades.

Certas obras ambientam-se em um mundo pseudomedieval, tentando para isso estabelecer bases narrativas realistas, com explicações detalhadas de índole histórica ou social que explicam, inclusive cientificamente, cada um dos lugares e situações que as compõem. Outras obras fogem desta relativa realidade para criar mundos sustentados pela imaginação e pela magia.

Nós, seres humanos trazemos impresso na base de nossa mente modelos de comportamento e formas de nos relacionar com o mundo que são chamados de arquétipos na psicologia analítica, como afirma o psiquiatra suíço Carl Gustav Jung9 . Os arquétipos confundem-se com a mitologia - e o herói é o mito, por assim dizer, mais permanente e cultivado por todas as culturas.

Os arquétipos junguianos podem ser considerados como avatares. Joseph Campbell defende a explicação do heroísmo, dizendo que este está na ação heroica e não no julgamento que possamos, por ventura, fazer da motivação do herói. Para ele, o heroísmo tem objetivo moral de salvar um povo, uma pessoa, ou mesmo de defender uma ideia. O herói sempre se sacrifica por alguma coisa e é aí que se encontra o cerne do ato, a importância do personagem, que o torna memorável e muitas vezes épico (CAMPBELL \& MOYERS, 1990).

Desde as epopeias sumérias e gregas, as viagens têm constituído um elemento indispensável para conceder o tom épico das narrativas. Tratam-se de viagens cansativas e acidentadas, às vezes erráticas, que as personagens devem superar, como ocorre na A epopéia de Gilgamesh e na Odisseia. O Senhor dos Anéis carrega também essa característica. Os livros tendem a começar com uma viagem e a terminar quando esta se conclui.

Uma segunda via para desenvolver a fantasia épica são os combates, guerras e batalhas. Muitos autores têm confiado na decisão de terminar suas histórias com batalhas

\footnotetext{
${ }^{9}$ Carl Gustav Jung foi um psiquiatra suíço fundador da psicologia analítica conhecido também como psicologia junguiana. A psicologia analítica tinha como base o contato prático com seus pacientes. Com essa prática e com contato com Sigmund Freud, dedicou-se a analisar os meios pelas quais o inconsciente se expressa. Em sua teoria, enquanto o inconsciente pessoal consiste fundamentalmente de material reprimido e de complexos, o inconsciente coletivo é composto fundamentalmente de uma tendência para sensibilizar-se com certas imagens, ou seja, símbolos que fazem parte de sentimentos profundos de apelo universal, os arquétipos: da mesma forma que animais e homens parecem possuir atitudes inatas, chamadas de instintos, também é provável que em nosso psiquismo exista um material psíquico com alguma analogia com os instintos.
} 
espetaculares, lutas tanto físicas como mágicas. Exemplos de finais apoteóticos não faltam: a batalha final da última parte de $O$ Senhor dos Anéis e O Retorno do Rei seguem esse caminho. Em A Sociedade do Anel temos a batalha às margens do Grande Rio, onde a sociedade de desfaz, quando Frodo decide seguir caminho para Mordor abalado sem os conselhos de Gandalf. Em As Duas Torres, a esperança se renova, com Gandalf retornando como o mago Branco, e duas importantes batalhas ocorrem. Em O Retorno do Rei, as batalhas decisivas ocorrem nos Campos do Pelennor e à frente do Portão Negro, no Campo de Cormallen.

Sobre histórias ambientadas em mundos possíveis, viagens e aventuras podemos citar nas próprias palavras de Tolkien, em sua tentativa de definir histórias de fadas:

A maioria das boas 'histórias de fadas' trata das aventuras dos homens no Reino Perigoso ou em seus confins sombrios. É natural porque, se os elfos são reais e de fato existem independentemente de nossas histórias sobre eles, então também isto certamente é verdade: a princípio, os elfos não estão interessados em nós, nem nós neles. Nossos destinos são distintos, e nossas trilhas raramente se encontram. Mesmo nas divisas do Belo Reino nós os encontramos somente em algum cruzamento fortuito de caminhos. (nota do autor: Isso também é verdadeiro, mesmo que sejam apenas criações da mente humana, 'verdadeiras' somente como reflexo, de um determinado modo, de uma das visões humanas da Verdade (TOLKIEN, 2010).

Definir histórias de fadas, sob o olhar de Tolkien, é uma tarefa complexa, porque as histórias de fadas não dependem de definição ou relato histórico de elfos ou fadas, mas da natureza do Belo Reino, que envolve aventura e perigo ao mesmo tempo:

O Belo Reino não pode ser capturado numa rede de palavras, porque uma de suas qualidades é ser indescritível, porém não imperceptível. (...) Por hora só direi isto: uma 'história de fadas' é aquela que resvala ou usa o Belo Reino, qualquer que seja sua finalidade principal - sátira, aventura, moralidade, fantasia. O próprio Belo Reino talvez possa ser traduzido mais proximamente de Magia - mas uma magia com disposição e poder peculiares, no polo mais afastado dos artifícios vulgares do mágico laborioso e científico. Há uma ressalva: se houver alguma sátira presente na narrativa, de uma coisa não se deve zombar: a própria magia. Nesse tipo de história ela precisa ser levada a sério, não deve ser motivo de riso nem de muitas explicações. $O$ conto medieval Sir Gawain e o Cavaleiro Verde é um exemplo admirável dessa seriedade (TOLKIEN, 2010).

O conto Sir Gawain e o Cavaleiro Verde, ao qual Tolkien se refere, é um romance em versos do século XVI escrito no chamado inglês médio. O personagem principal é Sir Gawain, um cavaleiro da távola redonda, sobrinho do rei Arthur. Juntamente com as lendas arturianas, 
a obra se inscreve no contexto da literatura medieval inglesa. Segundo a tradição descrita no Mabinogion - coletânia de manuscritos em galês medieval - Arthur ganhou forma na imaginação popular, por volta do século $\mathrm{X}$, aparecendo como imperador e/ou rei. No livro $O$ rei Arthur e os Cavaleiros da Távola Redonda, de Thomas Malory é dito que Artur estará entregue a Merlin guiado por seus conselhos. Diego Silva compara Arthur e Merlin com Aragorn e Gandalf em um artigo (SILVA, 2010) .

Considerando a figura de cavaleiro que luta pela lealdade e justiça, Aragorn se equipara a Artur com facilidade. Em algumas histórias sobre Artur, a sua espada, "Excalibur", quebra-se com um golpe contra Tristão e, depois, reconstrói-se. Aragorn recebe os fragmentos de Narsil que, em combate com Sauron, também se quebra:

Fui arauto de Gil-galad, e marchei com sua tropa. Estive na Batalha de Dagorlad diante do Portão Negro de Mordor, onde vencemos: pois à Lança de Gil-galad, e à Espada de Elendil, Aiglos e Narsil, ninguém podia resistir. Eu vi o último combate nas encontas de Orodruin, onde Gil-galad morreu, e Elendil caiu, e Narsil se quebrou sob seu corpo. Mas Sauron foi vencido, e Isildur cortou o Anel de sua mão com o fragmento do punho da espada do pai, e pegou-o para si (TOLKIEN, 2001).

Mais tarde os fragmentos da Narsil são usados para reforjar uma nova espada, no ano de 3019 da Terceira Era, em comemoração da descoberta e captura do Anel. Aragorn a chamou de Andúril - a Chama do Oeste - e a usou enquanto foi membro da Sociedade do Anel. A citação que se faz sobre a lenda da espada aparece em duas ocasiões nos escritos de $O$ Senhor dos Anéis: recitada por Bilbo, no conselho de Elrond, quando membros de diversas raças discutem os rumos do Anel e numa carta de Gandalf a Frodo, justificando a sua falta em Bri, confiando que ele e seus amigos seriam guiados por outro amigo, conhecido por Passolargo, que nada mais é do que Aragorn:

Certifique-se de que se trata do verdadeiro Passolargo. Há muitos homens estranhos na estrada. Seu nome verdadeiro é Aragorn.

Nem tudo que é ouro fulgura,

Nem todo o vagante é vadio;

$O$ velho que é forte perdura,

Raiz funda não sofre o frio.

Das cinzas um fogo há de vir,

Das sombras a luz vai jorrar; 
A espada há de, nova, luzir,

O sem-coroa há de reinar (TOLKIEN, 2001).

Gandalf, além de conselheiro e estrategista, tem função fundamental nos caminhos que percorrem toda a sociedade do anel, mesmo quando seus menbros tomam caminhos diferentes.

Outras proximidades com as lendas arturianas aparecem com relação ao próprio Conselho de Elrond. Nele, os representantes das raças da Terra-Média se reúnem em círculo em volta do Anel para discutirem o destino do objeto mágico. De forma semelhante, nas histórias do rei Artur, os membros da cavalaria da Távola Redonda sentam-se ao redor de uma mesa que fora criada sem cabeceira, para conceder igualdade aos seus membros da cavalaria. No conselho, Elrond dirige-se de forma igualitária aos membros da reunião.

Nas lendas arturianas há importantes referências ao Graal. O conto do Graal, escrito pelo francês Chrétien de Troyes, deu início a narrativas sobre o assunto de sua busca; a concessão de grandes poderes ao seu portador. Semelhante ao Graal, o Anel é um objeto central na trilogia de O Senhor dos Anéis, pois também impacta na vida do indivíduo que entra em contato com ele. Tanto o Graal quanto o Anel demandam uma busca em torno de um objetivo comum: exterminar o mal.

Ainda em relação ao termo "conto de fadas", Tolkien pensa que este é usado, em certos livros, de maneira equivocada. Se há fadas, bela família, anões e duendes estes serão apenas uma parte do conteúdo da narrativa. Muitos deles nem mesmo passam pelo Belo Reino ou deveriam ser incluídos. Essa discussão proposta por Tolkien nos leva a dois de seus propósitos: mostrar a complexidade em se definir histórias de fadas e as suas origens.

Tolkien acredita que narrativas que fazem uso do sonho (humano) para explicar acontecimentos, mesmo que o sonho seja relatado como uma história de fadas, não sejam propriamente histórias de fadas. Para o escritor, o sonho é alheio ao Belo Reino e pode liberar estranhos poderes da mente:

Às vezes um sonho real pode de fato ser uma história de fadas de tranquilidade e destreza quase élficas (...)" mas se o escritor disser que o que está escrito é algo imaginado durante o sono, cometerá o erro de defraudar o desejo principal no cerne do Belo Reino: “(...) a compreenção do feito prodigioso imaginado, não importa a mente que o conceba (TOLKIEN, 2001). 
A fantasia com frequência refugia-se no seio de mundos habitados por seres fantásticos ou mitológicos, como $\underline{\text { fadas, }}$ orcs ou elfos (a fantasia não se refugia nestes seres em si mesmos, mas são comumente parte do conteúdo da narrativa). Boa parte deles se encontra na mitología germânica e escandinava, como o caso dos elfos. Outros, não menos conhecidos, como as harpias, se oiginam dos povos eslavos. Devemos às lendas asiáticas, os dragões à mitologia árabe, os demônios. Muitas obras prescedem totalmente de criaturas fantásticas, como em "Eragon" $"$.De todas elas, talvez as criaturas que aparecem com mais assiduidade no gênero sejam os dragões.

A magia é um recurso muito presente a este gênero nas narrativas de fantasia, a ponto de muitas obras se sustentarem basicamente por meio dela. É o caso da série Harry Potter, já citada. Intimamente unidas à magia estão as profecias, que são tão importantes como a própria magia; às vezes até mais. É habitual nestas narrativas, encontrar destinos que precisam se cumprir ou, mais raramente, que necessitam ser impedidos de se efetivar. Por esse motivo, justificam-se as missões, as relações pessoais e as guerras. Não só em Harry Potter ${ }^{11}$ é possível perceber isso, como em nosso escopo, as histórias de Tolkien. Um exemplo é o capítulo "O Espelho de Galadriel", em que a elfa mística mostra a Frodo o que pode acontecer, caso ele falhe na missão que lhe foi designada. O Anel do Poder veio até ele, e Frodo escolheu no Conselho de Elrond carregar o fardo de Portador do Anel e jogá-lo no fogo da Montanha da Perdição, onde o anel foi forjado secretamente para controlar todos os demais anéis mágicos. Se em Tolkien Frodo é o designado à tarefa que pode lhe custar a vida, em Harry Potter, a personagem de Harry passa pela mesma situação, confrontando o vilão Voldemort, que outrora dividiu seu poder com ele ao tentar matá-lo quando criança. Se em "O Senhor dos Anéis" Tolkien representou simbolicamente o mal, por meio de um anel; na litaratura de Rowling, o mal é representado pela cicatriz no rosto do garoto Harry.

Existe, a partir de Tolkien, uma tendência a converter os mundos imaginários (heterocósmicos) em mundos reais, geralmente como forma de concluir a narrativa e buscar sentido para ela, sob o conhecimento do que entendemos como realidade. É conhecida a língua élfica inventada pelo escritor, além de seus muitos apêndices, notas e listas tornando-as “científicas”, paupáveis e possíveis de serem usadas, conferindo, assim, sentido à linguagem.

\footnotetext{
${ }^{10}$ Eragon,é um livro escrito pelo escritor norte-americano Christopher Paolini.

${ }^{11}$ Harry Potter é referenciado aqui pela contemporaneidade com os livros de Tolkien. 
Para além de manter uma coerência narrativa, é um trabalho adicional árduo, que atua profundamente na história e a enriquece.

Em muitas narrativas, o autor opta por utilizar documentações históricas, geográficas ou sociais totalmente fictícias, como ocorre em grande parte dos livros de Tolkien. Há autores também que chegam a criar livros e atlas específicos do mundo a tratar, utilizando-os como complemento à história. A coerência com o mundo real que deve ter uma história de fantasia épica (ou mundo heterocósmico) é próxima de um realismo sutil. Nesse sentido, a obra de Tolkien talvez tenha sido uma das que mais aproximou de uma mitologia, de um entendimento de mundo muito passível de ter sido real.

Ainda que em uma extensão muito incomum, O Senhor dos Anéis é uma história de fadas. Como bem reflete o autor em Sobre Histórias de Fadas, uma narrativa, para ter esse status, não necessita ter nenhuma fada entre os personagens. Tolkien ressalta, inclusive, que um bom conto de fadas é sobre aventuras de homens no Belo Reino. Esse pensamento é o suficiente para entendermos tanto $O$ Hobbit quanto $O$ Senhor dos Anéis como exemplos de contos de fadas subcriados, uma vez que ambos apresentam personagens em aventuras em um universo não bem explorado como o nosso.

Seguindo esse raciocínio, é ideal que os contos de fadas sejam apresentados como verdadeiros, não como sonhos ou ilusões. Essa espécie de veracidade é necessária para que "ganhe vida" diante de nossa interpretação e para que o leitor não se questione quanto ao mundo do qual está diante

Talvez seja bastante comum encontrar leitores (não especializados) a considerar $O$ Senhor dos Anéis como uma obra única, sem precedentes da literatura moderna. A tendência do fã é, quase sempre, idealizar a ponto de exaltar a obra fortemente. Apesar de alguns críticos e estudiosos, como Ronald Kyrmse e biógrafos como Humprey Carpenter, apontarem as profundidades da obra, da riqueza e estilo complexo com relação aos detalhes; para alguns historiadores, Tolkien pode não ter feito nada mais do que um romance fantástico, já que as suas intenções de escrita se pautaram no apreço que ele tinha por histórias assim. Ele conta uma interessante história de aventuras, que não tem implicação simbólica alguma com nenhum fato histórico, com nenhum contexto específico e muito menos serve a algum tipo de retórica ou busca de convencimento de alguma ideologia. Os escritos de Tolkien tratam fortemente da condição humana. 
Assim, a marca da fantasia de Tolkien, vai além dos sentidos alegóricos, que alguns insistem em encontrar, como a suposta associação da Guerra do Anel com a Segunda Guerra Mundial. Lin Carter pode nos ajudar a entender os caminhos da narrativa de Tolkien ao afirmar que:

A marca da verdadeira fantasia, seu selo de autenticidade, pela qual ela pode ser diferenciada da fraude e da imitação, é a qualidade de "prazer": o prazer do criador na coisa que ele fez, quando bem-feita; o prazer do leitor que foi enfeitiçado pelo subcriador e vai morar durante algum tempo dentro de um Mundo Secundário no que foi feito com amor e cuidado (CARTER, 2003).

Assim para Lin Carter, o objetivo de Tolkien era mais do que convencer que o Mundo Secundário subcriado é um mundo nosso em um período muito anterior ao que vivemos, ou que, ao usar dragões, trolls, anões e elfos, sua intenção fosse unicamente essa. Cita que "quando fala das realidades subjacentes, Tolkien provavelmente alude às verdades eternas da natureza humana" (CARTER, 2003).

Joseph Campbell diz que nos mitos é que se encontra as pistas para as potencialidades espirituais da vida humana, e mitos são capazes de tocar o íntimo como algo verdadeiro, e que isso, todo homem é capaz de reconhecer. Além disso, as imagens míticas passam de geração para geração, inconscientemente:

Isso é absolutamente fascinante, porque elas falam do profundo mistério de você mesmo e de tudo o mais. É um mysterium, um mistério, tremendum et fascinans - tremendo, horrível, porque destrói todas as noções fixas que você tem das coisas, e ao mesmo tempo é absolutamente fascinante, porque diz respeito à sua própria natureza, ao seu ser (CAMPBELL \& MOYERS, 1990).

A visão de Campbell contempla a ideia defendida por Carter de que Tolkien buscou em $O$ Senhor dos Anéis transmitir um sentido moral da condição humana. Como ele mesmo cita, os personagens ciumentos, cobiçosos têm sede de poder e são punidos. Os humildes sofrem, os honestos são recompensados por sua nobreza. O conceito pode ser ultrapassado, mas se assim é, ele aponta que, então, todas as literaturas moralistas devem ser chamadas de ultrapassadas. Acreditamos que essa moral está muito presente nas entrelinhas das obras de Tolkien e que parece que ele, mesmo sem essa intenção, criou um ensinamento por meio dela. 
Os enredos dos livros de Tolkien não deixam espaço para assuntos sem sentido. Em $O$ Senhor dos Anéis não há cenas improvisadas para cobrir lacunas ou ambiguidades, muito menos acontecimentos previsíveis. Há pura imaginação e uma criatividade livre, regadas a humor, e muitos detalhes importantes, culminando numa perspectiva de em um provável "fim” trágico, porém esperançoso. Há, ainda, acontecimentos que têm consistência filosófica e lógica, como propõe Greggersen em seu livro O Senhor dos Anéis: da fantasia à ética. Nesta obra, a autora chama atenção para a profundidade filosófica da literatura de Tolkien e afirma que não se trata de quaisquer escritos divagantes esporádicos, penosos ou abstratos sobre "fórmulas mágicas". Obras que não se configuram dessa maneira podem até impressionar leitores desavisados, mas pouco acrescentariam às suas vidas, conforme afirma Greggersen. Essas obras serviriam, no máximo, como um passatempo, ou ilusões que podem levar até a angústia existencial.

É precisamente essa angústia que $O$ Senhor dos Anéis está interessado em tratar, embora nem todos gostem do remédio oferecido por Tolkien. Quem sabe uma leitura mais profunda possa estimulá-los a ingeri-lo sem maiores traumas (GREGGERSEN, 2003).

Greggersen também aponta noções de moralidade e ética na obra $O$ Senhor dos Anéis, afirmando que os escritos do professor geram fascínio em quem lê suas obras e se permite “deixar levar" pela narrativa, que vai muito além de uma mera história de fantasia. Aprendemos, com o legado literário de Tolkien, que é possível que um Mundo Secundário completo sirva de modelo para que possamos nos maravilhar ao mesmo tempo em que podemos reconhecer nele algo do nosso próprio mundo e, também, reconhecer a nós mesmos através dos personagens, de suas fraquezas e forças. Tolkien mostra, ainda, que o mais humilde e isolado ser, avesso a aventuras, pode superar-se e sair em busca de novas coisas, triunfar sob obstáculos e voltar para casa, estando confortável outra vez, porém rico em experiências e sabedoria, como ocorre com Bilbo Baggings, em "O Hobbit"; um personagem simples e acomodado que nunca esperaria uma aventura como a que viveu; ou mesmo o seu sobrinho, Frodo, um ser que, embora minúsculo, parte em busca de salvar o mundo com muita coragem, tornando-se o herói da saga, na sequência de $O$ Senhor dos Anéis.

Por meio das narrativas de Tolkien, aprendemos que o mais nobre dos elfos pode sucumbir à soberba e trazer para si um terrível destino e que personagens rudes e que aparentam pouca confiança podem esconder homens de grande solidariedade e bravura, como Aragorn 
quando era apenas um forasteiro a se juntar aos hobbits antes de chegarem a Valfenda; ou mesmo Èowyn que, por trás de uma aparência frágil feminina, esconde uma grande guerreira.

Outro ponto interessante que Tolkien nos mostra em sua obra é que o poder seduz e corrompe a todos igualmente. Só os nobres e humildes são capazes de resistir. Tolkien mostra, ainda, que devemos agir como guardiões do mundo, seja ele natural, espiritual ou humano, pois depende de nós resguardá-lo para as gerações que virão Qualidades como companheirismo, persistência, honestidade, amizade, entre outros podem e devem nos conduzir ao êxito de nossas buscas, mesmo com os percalços que o mundo nos impõem. Aprendemos, também, com os livros de Tolkien que acima de tudo é necessário ter esperança, pois a ajuda vem do lugar que menos esperamos encontrá-la.

Em $O$ senhor dos anéis, Tolkien mostra que os mitos da natureza humana não têm fim, as histórias nunca terminam, apenas trocam de personagens quando esses cumprem seu papel, como o trecho abaixo sugere:

- (...) Os feitos corajosos das velhas canções e histórias, Sr. Frodo: aventuras, como eu as costumava chamar. Costumava pensar que eram coisas à procura das quais as pessoas maravilhosas das histórias saiam, porque as queriam, porque eram excitantes e a vida era um pouco enfadonha, um tipo de esporte, como se poderia dizer. Mas não foi assim com as histórias que realmente importaram, ou aquelas que ficam na memória. As pessoas parecem ter sido simplesmente embarcadas nelas, geralmente - seus caminhos apontavam naquela direção, como se diz. Mas acho que eles tiveram um monte de oportunidades, como nós, de dar as costas, apenas não o fizeram. E, se tivessem feito, não saberíamos, porque eles seriam esquecidos. Ouvimos sobre aqueles que simplesmente continuaram - nem todos para chegar a um final feliz, veja bem; pelo menos não para chegar àquilo que as pessoas dentro de uma história, e não fora dela, chamam de final feliz. O senhor sabe, voltar para casa, descobrir que as coisas estão muito bem, embora não sejam exatamente iguais ao que eram — como aconteceu com o velho Sr. Bilbo. Mas essas não são sempre as melhores histórias de se escutar, embora possam ser as melhores histórias para se embarcar nelas! Em que tipo de história teremos caído?

- Também fico pensando - disse Frodo. - Mas não sei. E é assim que acontece com uma história de verdade. Pegue qualquer uma de que você goste. Você pode saber, ou supor, que tipo de história é, com final triste ou final feliz, mas as pessoas que fazem parte dela não sabem. E você não quer que elas saibam. 
- Não, senhor, claro que não. Veja o caso de Beren: ele nunca pensou que ia pegar aquela Silmaril da Corôa de Ferro em Thangorodrim. E apesar disso ele conseguiu, e aquele lugar era pior e o perigo era mais negro que o nosso. Mas é uma longa história, é claro, e passa da alegria para a tristeza e além dela e a Silmaril foi adiante e chegou a Eärendil. E veja, senhor, eu nunca tinha pensado nisso antes! Nós temos — o senhor tem um pouco da luz dele naquela estrela de cristal que a Senhora lhe deu! Veja só, pensando assim, estamos ainda na mesma história! Ela está continuando. Será que as grandes histórias nunca terminam?

- Não, nunca terminam como histórias — disse Frodo. - Mas as pessoas nelas vêm e vão quando seu papel termina. Nosso papel vai terminar mais tarde ou mais cedo (TOLKIEN, 2001).

Sobre este longo trecho, notamos que as histórias heroicas nunca terminam, segundo Tolkien. Campbell diz que um herói é alguém que coloca a sua própria vida em risco por algo maior que ele mesmo. Há dois tipos de herói, segundo este estudioso do mito, aquele que pratica um ato de coragem durante uma batalha, e aquele que lida com a vida espiritual e retorna com uma mensagem. Com Frodo, temos esses dois tipos de herói inseridos num só personagem. Destruir o anel em Mordor pode ser lido como um ato de coragem. Quando retorna ao condado, ele conta a sua parte na aventura em um livro deixado por seu tio Bilbo. Ao terminar os escritos, ele parte em um navio especial, dando a entender que desempenhou seu papel e é hora de ir embora.

Frodo pode ser visto como o típico herói que se sacrifica por salvar algo maior que ele. A metáfora de que Frodo é um personagem menor que um anão, parece-nos um indicativo visual de sacrifício por esse algo bem maior que ele: Frodo salva a Terra-Média de todo o mal e devolve aos povos a liberdade que lhes foi tirada pelo poder de controle de Sauron, muito tempo antes dele. Juntamente com Frodo, Aragorn divide a disposição de herói do tipo que salva vidas em batalhas e no fim lidera um povo desamparado no pós-guerra. Novamente, ele representa o sacrifício dado em prol de algo maior. Em $O$ Hobbit, a construção do caráter de Bilbo segue esse aspecto heroico, pois o mesmo se encontra em uma aventura da qual age conforme os desafios aparecem. Dessa forma, voltamos à Campbell que cita: "A aventura é simbolicamente uma manifestação do seu caráter. Até a paisagem e as condições ambientes se harmonizam com sua presteza" (CAMPBELL \& MOYERS, 1990).

Ao contrário do que se possa pensar, entendemos - assim como Campbell - que nós precisamos sempre de novos mitos. Enquanto alguns de nós acreditam que não passamos de 
um padrão previsível que responde a estímulos, outros cultuam celebridades como heróis. É este o ponto chave que acreditamos ser a razão da qual Tolkien foi tão bem sucedido com seus escritos de um Mundo Secundário. Todas as histórias de Arda têm um herói que parte, realiza e retorna, num esquema intrinsecamente coerente. Essas histórias são meticulosamente construídas, refletem uma condição humana na qual nos identificamos e nos cativamos. Encontramos pontos na história que nos colocam como aparentes participantes dela, em confronto com personagens que pensam e agem conforme alguns de nossos anseios, e outros que divergem totalmente de nosso modo de ver as coisas

"Não é necessário acreditar que houve um rei Artur para aprender o significado das histórias da Távola Redonda (...)” (CAMPBELL \& MOYERS, 1990). Acreditamos, então, que é quando entendemos e nos identificamos com os significados das histórias que atingimos o encantamento que Tolkien tanto esperava de seus leitores, pois entendia esse encantamento como condição necessária para que uma obra fosse bem composta. Seu legado literário acabou sendo mais que bem sucedido, prova disso é o fato de que desde a primeira publicação de $O$ Hobbit, em 1937, suas histórias são recriadas, citadas e ainda lidas pelas novas gerações. Ler Tolkien é dar continuidade e vida aos mitos e ao mundo da literatura maravilhosa, de fantasia.

\section{Referências}

CAMPBELl, J. \& MOYERS, B. O poder do mito. São Paulo: Palas Athena, 1990.

CARTER, L. O senhor do Senhor dos Anéis: o mundo de Tolkien. Tradução de Alves Calado. Rio de Janeiro: Record, 2003.

ÉARENDEL. In: The Tolkien Wiki Community. Disponível em: http://www.thetolkienwiki.org/wiki.cgi?Mythology/\%C9arendel (Acesso em 8 de janeiro de 2018).

GREGGERSEN, G. O senhor dos anéis: da fantasia à ética. Viçosa, MG: Ultimato, 2003. KYRMSE, R. Explicando Tolkien. São Paulo: Martins Fontes, 2003.

LOPES, R. J. Tolkien, o Filólogo. Revista O Universo Fantástico de Tolkien, Ano 1, número 3, p. 4-5. Camargo \& Moraes Editora, 2002?.

SILVA, D. Comparando Tolkien e lendas arturianas. In: Dúvendor: um tributo a Tolkien. 6 jan, 2010. Disponível em: 
http://duvendor.com.br/portal/index.php?option=com_content $\&$ view=article $\& i d=656 \% 3 \mathrm{Aco}$ $\underline{\text { mparando-tolkien-e-lendas-arturianas \&catid=63\%3Adiego-silva } \& \text { Itemid=178 }}$ (Acesso em Janeiro de 2018).

TOLKIEN, J. R. R. O Senhor dos Anéis. Tradução: Lenita Maria Rímoli Esteves, Almiro Pisetta. 1. ed. São Paulo: Martins Fontes, 2001.

TOLKIEN, J. R. R. Sobre Histórias de Fadas. São Paulo: Conrad Editora do Brasil, 2010.

WHITE, M. Tolkien: uma biografia. Tradução: Alda Porto. Rio de Janeiro: Imago Ed., 2002.

Artigo recebido em: 02/08/2018

Artigo aprovado em: 10/09/2018 